\title{
Evolution histories of transcrustal magma system recorded in crystal cargo: the case of mafic-felsic dykes in Northern Tibet
}

\author{
FUHAO XIONG ${ }^{1 *}$, CHANGQIAN MA ${ }^{2}$
}

${ }^{1}$ College of Earth Science, Chengdu University of Technology, Chengdu 610059, China (*correspondence: xiongfuhao2014@cdut.edu.cn)

${ }^{2}$ State Key Laboratory of Geological Processes and Mineral Resources, China University of Geosciences, Wuhan 430074, China (cqma@cug.edu.cn)

Crystal cargos in transcrustal magmatic system record the physicochemical changes in the host melt and play a key role in construction of the evolution histories of magma reservoirs. Here, through a comprehensive study of petrology and geochemistry, as well as EPMA and LA-ICPMS elemental mapping of mineral crystals (amphibole, pyroxene and plagioclase) from Triassic mafic-felsic dykes in Northern Tibet, the architecture and spatial-temporal evolution of the transcrustal magma system was constructed. Geochemical and Sr-Nd-Hf isotopic data indicate the parental magma of the mafic dykes was derived from enriched lithospheric mantle. This mafic magma underplated the crust and underwent varying degrees of magma recharging, crustal assimilation, and fractional crystallization dominated by olivine, pyroxene, and hornblende at lower crustal level (ca. 26-32 $\mathrm{km})$. The high Chromium (Cr) zonations in clinopyroxene from mafic dykes reveals punctuated episodes of recharging of mafic magma at depth. The evolved mafic magmas injected into a mid-crustal felsic magma mush reservoir (ca. 9-18 km), followed by rejuvenating and magma mixing as recorded in complex zoing of crystal cargos. This study shows that the transcrustal magma system, which controls the compositions of several dispersed but interconnected magma reservoirs, is the key to understanding the compositional diversity and igneous petrogenesis in continental arcs. 